\title{
ADUBAÇÃO NITROGENADA E IRRIGAÇÃO NO MARACUJAZEIRO-AMARELO. I. PRODUTIVIDADE E QUALIDADE DOS FRUTOS ${ }^{1}$
}

\author{
ALMY JUNIOR CORDEIRO DE CARVALHO ${ }^{2}$, DONIVALDO PEDRO MARTINS ${ }^{3}$, \\ PEDRO HENRIQUE MONNERAT ${ }^{4}$ e SALASSIER BERNARDO ${ }^{4}$
}

\begin{abstract}
RESUMO - Conduziu-se um experimento em Campos dos Goytacazes, RJ, no período de dezembro de 1995 a junho de 1997, para avaliar o efeito da adubação nitrogenada, sob diferentes lâminas de irrigação, na produtividade e na qualidade dos frutos do maracujazeiro-amarelo. Testaram-se quatro doses de nitrogênio $\left(50,250,450\right.$ e 650 g planta $^{-1}$ ano $\left.^{-1} \mathrm{de} \mathrm{N}\right)$, utilizando a uréia como fonte de $\mathrm{N}$, sob seis lâminas de irrigação $(0,25,50,75,100$ e $125 \%$ da ET - evapotranspiração de referência), num esquema fatorial $4 \times 6$, com três repetições. Utilizou-se um sistema de irrigação por gotejamento. Não houve variação na produtividade quando o $\mathrm{N}$ foi aplicado sob lâminas de irrigação de 0,25 , 100 e $125 \%$ da $\mathrm{ET}_{0}$. A produtividade máxima de frutos, $41,3 \mathrm{t} \mathrm{ha}^{-1}$, foi obtida quando se aplicaram $290 \mathrm{~g} \mathrm{planta}^{-1}$ ano $^{-1}$ de N, sob uma lâmina de irrigação de $75 \%$ da ET, o que correspondeu a uma lâmina total de água (irrigação + precipitação efetiva) de $1.293 \mathrm{~mm}$. A adubação nitrogenada influenciou o número de frutos e não apresentou influência sobre o peso médio e outras características qualitativas dos frutos. A irrigação influenciou a produtividade, o peso médio, o comprimento e o diâmetro dos frutos.
\end{abstract}

Termos para indexação: adubos nitrogenados, nutrientes minerais, fertilidade do solo, fruto, Passiflora edulis, fruticultura.

\section{NITROGEN FERTILIZATION AND IRRIGATION DEPTHS IN YELLOW PASSIONFRUIT. I. YIELD AND FRUIT QUALITY}

\begin{abstract}
A field experiment was carried out, in Campos dos Goytacazes, RJ, Brazil, from December, 1995 to June, 1997, to evaluate the effect of nitrogen fertilization, under different irrigation depths, on yield and fruit quality of yellow passionfruit. Four nitrogen levels (50, 250, 450 and $650 \mathrm{~g} \mathrm{plant}^{-1}$ year $^{-1}$ of $\left.\mathrm{N}\right)$ were tested, using urea as the source of $\mathrm{N}$, under six irrigation depths $(0,25$, $50,75,100$ and $125 \%$ of $\mathrm{ET}_{0}$ - reference crop evapotranspiration for grass), at $4 \times 6$ factorial scheme with three replications. A dripping irrigation system was used. There was no yield response due to increasing nitrogen levels when $0,25,100$ and $125 \%$ of $\mathrm{ET}_{0}$ were applied. Maximum fruit yield (41.3 ton ha ${ }^{-1}$ ) was obtained when $290 \mathrm{~g} \mathrm{plant}^{-1}$ year $^{-1}$ of $\mathrm{N}$ was applied under an irrigation depth close to $75 \%$ of $\mathrm{ET}_{0}$, which corresponded to a total of $1,293 \mathrm{~mm}$ of applied water (irrigation + effective rainfall). Nitrogen fertilization influenced the number of fruit and did not show any effect on either average weight or other fruit qualitative characteristics. Irrigation depth had great influence on fruit yield, average weight, length and diameter.
\end{abstract}

Index terms: nitrogen fertilizers, mineral nutrients, soil fertility, fruit, Passiflora edulis, fruit growing.

${ }^{1}$ Aceito para publicação em 5 de julho de 1999

Extraído da tese de doutorado do primeiro autor apresentada à Universidade Estadual do Norte Fluminense (UENF).

${ }^{2}$ Eng. Agrôn, D.Sc., Prof. Associado, LFIT/CCTA/UENF, CEP 28015-620 Campos dos Goytacazes, RJ. E-mail: almy@uenf.br

${ }^{3}$ Eng. Agrôn., D.Sc., Governo da Bahia-Seplantec-Car, CEP 41100-170 Salvador, BA.

E-mail: donivald@cpu0011.ba.gov.br

${ }^{4}$ Eng. Agrôn., Ph.D., Prof. Titular, LFIT/CCTA/UENF.

\section{INTRODUÇÃO}

A partir de 1970, o cultivo do maracujazeiro-amarelo (Passiflora edulis f. flavicarpa Deg.) no Brasil tornou-se uma atividade com maior intensidade comercial, e, atualmente, com uma evolução gradual, proporciona bons rendimentos de divisa ao Brasil, que é hoje o primeiro produtor mundial desta fruta, 
com umaárea plantada, em 1995 , próxima de 39.500 ha, representando um aumento de, aproximadamente, $55 \%$ entre a área plantada em 1990 e a verificada em 1995 (Agrianual, 1999).

Entretanto, no mesmo período, verificou-se um decréscimo em torno de $19 \%$ na produtividade de frutos desta cultura (Agrianual, 1999). Assim, a contínua expansão dos plantios tem gerado uma demanda por tecnologias de produção mais adequadas, capazes de elevar a produtividade e a rentabilidade dos pomares.

Nesse contexto, adubações e irrigações, quando corretamente aplicadas, são práticas altamente recomendadas, por influenciar direta e positivamente a produtividade. Porém, a falta de informações sobre os níveis adequados de fertilizantes e irrigações a serem aplicados em cada condição de plantio, não tem permitido, na maioria dos casos, inferências a respeito desses insumos, o que tem prejudicado o desenvolvimento da cultura.

Alguns estudos examinaram a nutrição com nitrogênio (N) em maracujazeiros (Aguirre, 1977; Baumgartner et al., 1978; Menzel et al., 1991). Gilmore (1983) e Sale (1988), citados por Menzel et al. (1991), sugerem que o excesso de N pode estimular o crescimento vegetativo e inibir o florescimento, mas isto não foi demonstrado em nenhum dos trabalhos citados acima, possivelmente em virtude das estreitas faixas de suprimento de N. Deve-se considerar, também, que entre esses trabalhos nem todos utilizaram o maracujazeiro-amarelo; em alguns deles foram utilizados o maracujazeiro-roxo e o maracujá-açu $(P$. quadrangularis L.)

Sobre a adubação do maracujazeiro existe pouca informação, embora essa prática seja importantíssima para pomares de elevada extração e exportação de nutrientes, principalmente os instalados em solos arenosos e pouco férteis. Silva (1994), analisando trabalhos de vários autores, observou grande variação nas recomendações de adubação nitrogenada, existindo indicação de 30 a $320 \mathrm{~g} \mathrm{planta}^{-1} \mathrm{ano}^{-1}$ de N. Haag et al. (1973) utilizaram $113 \mathrm{~g} \mathrm{planta}^{-1} \mathrm{ano}^{-1}$ de N e obtiveram uma produtividade de, aproximadamente, $10 \mathrm{tha}^{-1}$.

Partridge (1972) e Marchal \& Bourdeaut (1972), citados por Menzel et al. (1993), encontraram respostas positivas à fertilização com $\mathrm{N}$ e $\mathrm{K}$.
Baumgartner et al. (1978) também comprovaram uma resposta positiva ao $\mathrm{N}, \mathrm{P}$ e $\mathrm{K}$ no primeiro ano de produção, e ao N e P no segundo ano de produção. Por outro lado, trabalhos realizados por Faria et al. (1991) e Müller (1977) não observaram respostas do maracujá à fertilização com N, P e K.

O bom aproveitamento dos fertilizantes pela planta depende muito de adequada disponibilidade de água. A absorção de alguns nutrientes parece ser marcadamente prejudicada pela falta de água. Entretanto, o excesso de água pode elevar em demasia as perdas causadas pela lixiviação de nutrientes, tais como N $\left(\mathrm{NO}_{3}^{-}\right.$) e K (Raij, 1991).

$\mathrm{Na}$ cultura do maracujazeiro, a falta de umidade no solo determina queda das folhas e dos frutos na fase inicial de desenvolvimento, e pode causar, na fase final de desenvolvimento, enrugamento em frutos verdes e grandes. A irrigação é prática pouco estudada para esta cultura, mas o seu uso pode prolongar o período de produção, aumentar a produtividade e melhorar a qualidade dos frutos (Ruggiero et al., 1996).

Menzel et al. (1986), cultivando o maracujazeiro em estufa, verificaram que quando submetida a diferentes níveis de estresses hídricos, a planta apresentava um decréscimo significativo na produção de matéria seca antes mesmo do aparecimento de qualquer sintoma visível. Os mesmos autores verificaram, ainda, que um pequeno nível de estresse de umidade pode limitar severamente o crescimento vegetativo e o potencial de produção, concluindo que a irrigação em maracujazeiros deveria manter o perfil de umidade do solo próximo à capacidade de campo, principalmente durante o florescimento. Como efeito da falta de água no solo, tem-se a redução da extensão total dos ramos, decorrente, esta, da redução do número de nós e do comprimento dos internós. Isto, por sua vez, afeta o número de botões florais e flores abertas.

A irrigação regular permite a floração e a frutificação quase continuamente, desde que os outros fatores não sejam limitantes. O requerimento de água é elevado quando o fruto se encontra próximo da maturação. O estresse hídrico durante o desenvolvimento do fruto pode levar a decréscimos no peso e no volume de polpa, murcha e, por fim, à queda dos frutos (Teixeira, 1989). 
O objetivo do presente trabalho foi avaliar o efeito da adubação nitrogenada com diferentes lâminas de irrigação, sobre a produtividade e algumas características qualitativas do fruto do maracujazeiro-amarelo.

\section{MATERIAL E MÉTODOS}

O experimento foi instalado no município de Campos dos Goytacazes, RJ, em solo do tipo Podzólico, desenvolvido a partir de sedimentos terciários, com camada superficial arenosa, horizonte B textural e relevo suave ondulado, que representa bem as condições edafoclimáticas das áreas onde se cultiva o maracujazeiro-amarelo na região Norte Fluminense. A capacidade de campo do solo, até a profundidade de $40 \mathrm{~cm}$, foi estimada em $13 \%$ do volume e o ponto de murcha permanente em $6,5 \%$ de volume.

A análise do solo, por ocasião do plantio, apresentava as seguintes características nas camadas de 0 a 20 e 20 a $40 \mathrm{~cm}$, respectivamente: $\mathrm{pH}$ em $\mathrm{H}_{2} \mathrm{O}(1: 2,5)=5,6$ e 5,4; 21 e $6 \mathrm{mg} \mathrm{kg}^{-1}$ de $\mathrm{P} ; 20$ e 12 mmol $_{\mathrm{c}} \mathrm{kg}^{-1}$ de $\mathrm{Ca} ; 12$ e 8 mmol $_{\mathrm{c}} \mathrm{kg}^{-1}$ de $\mathrm{Mg} ; 0,8$ e 0,3 mmol $_{\mathrm{c}} \mathrm{kg}^{-1}$ de $\mathrm{K} ; 0,3$ e $0,3 \mathrm{mmol}_{\mathrm{c}} \mathrm{kg}^{-1}$ de $\mathrm{Na} ; 0$ e 0 mmol $_{\mathrm{c}} \mathrm{kg}^{-1}$ de $\mathrm{Al} ; 3,3 \mathrm{e}$ 23 mmol $_{\mathrm{ckg}^{-1}} \mathrm{de} \mathrm{H}+\mathrm{Al} ; 6$ e $4 \mathrm{~g} \mathrm{~kg}^{-1}$ de carbono; $1,25 \mathrm{e}$ $1,3 \mathrm{dS} \mathrm{m}^{-1}$ de condutividade elétrica; 240 e $200 \mathrm{~g} \mathrm{~kg}^{-1} \mathrm{de}$ areia fina; 520 e $460 \mathrm{~g} \mathrm{~kg}^{-1}$ de areia grossa; $30 \mathrm{e} 30 \mathrm{~g} \mathrm{~kg}^{-1} \mathrm{de}$ silte; 210 e $310 \mathrm{~g} \mathrm{~kg}^{-1}$ de argila.

A água utilizada na irrigação apresentava, em fev./96 e ago./97, respectivamente, as seguintes características químicas: $\mathrm{pH}=6$ e 4,5;0,75 e $0,66 \mathrm{dS} \mathrm{m}^{-1}$ de condutividade elétrica; 236 e $167 \mathrm{mg} \mathrm{L}^{-1}$ de cloreto; 20 e $5 \mathrm{mg} \mathrm{L}^{-1} \mathrm{de} \mathrm{Ca}$; 25 e $15 \mathrm{mg} \mathrm{L}^{-1}$ de Mg; 4 e 4,5 mg L-1 de K; 45 e $80 \mathrm{mg} \mathrm{L}^{-1}$ de Na. Segundo Bernardo (1995) a água é classificada como $\mathrm{C} 2 \mathrm{~S} 1 \mathrm{e}$, sendo assim, pode ser usada para plantas com razoável tolerância a sais, sempre que o solo permitir um grau moderado de lixiviação, e com pequena possibilidade de elevar o Na trocável no solo a níveis perigosos

O delineamento experimental adotado foi o de blocos casualizados, em esquema fatorial $4 \times 6$, com três repetições. Os tratamentos utilizados corresponderam a quatro doses de $\mathrm{N}\left(50,250,450\right.$ e $650 \mathrm{~g}_{\text {planta }}{ }^{-1}$ ano $^{-1}$ de $\left.\mathrm{N}\right)$, na forma de uréia, sob seis lâminas de irrigação $(0,25,50,75$, 100 e $125 \%$ da evapotranspiração de referência $-\mathrm{ET}_{0}$ ), que corresponderam a lâminas totais de água (irrigação + precipitação efetiva entre mar./96 e jun./97) a 826, 1.041, 1.195, $1.293,1.481 \mathrm{e} 1.733 \mathrm{~mm}$ de água, respectivamente. As parcelas foram constituídas por três fileiras com 24 plantas, em espaçamento de $3 \times 2 \mathrm{~m}$, considerando-se as seis plantas como úteis.
Todos os tratamentos receberam uma dose constante de $35 \mathrm{~g}$ de $\mathrm{P}$, na forma de superfosfato simples, $25 \mathrm{~g}$ de $\mathrm{K}$, na forma de cloreto de potássio, e $50 \mathrm{~g}$ de FTE-BR12, incorporados na cova 30 dias antes do plantio. Foram aplicados 10 e 16,6 g planta $^{-1}$ de $\mathrm{N}$ e K, respectivamente, aos 30, 60 e 90 dias após o plantio. Os adubos, em cobertura, foram aplicados numa faixa de 30 a $40 \mathrm{~cm}$ de distância do colo da planta, espalhados numa faixa de 20 a $30 \mathrm{~cm}$ de largura ao redor da planta. As doses de N, correspondentes aos tratamentos, foram divididas em dez parcelas iguais durante o ano, entre abril de 1996 e abril de 1997, omitindo-se as aplicações nos meses de julho de 1996 e janeiro de 1997. Por ocasião da aplicação do adubo nitrogenado, aplicou-se uma dose constante de $50 \mathrm{~g} \mathrm{planta}^{-1}$ de $\mathrm{K}$, totalizando $500 \mathrm{~g}_{\text {planta }}{ }^{-1}$ ano $^{-1}$ de $\mathrm{K}$

O plantio foi realizado em dezembro de 1995 e as plantas foram conduzidas no sistema de espaldeira vertical, com um fio de arame, a 1,8 $\mathrm{m}$ de altura em relação ao nível do solo. Foram realizados os tratos culturais que se fizeram necessários, tais como controle de plantas daninhas e tratamentos fitossanitários. Utilizaram-se, preventivamente, pulverizações com fungicidas à base de oxicloreto de cobre, para controle de algumas fitomoléstias, como a bacteriose e a verrugose

Nos tratamentos com irrigação, a água foi aplicada, inicialmente, através de um sistema de gotejamento por tubogotejador denominado Queen Gil. Em setembro de 1996, trocou-se o sistema de irrigação por outro com gotejadores autocompensantes do tipo Katif, com vazão de $3,75 \mathrm{~L} \mathrm{~h}^{-1}$. O controle do volume aplicado por parcela foi feito através de hidrômetros instalados nas linhas de distribuição do sistema. Um atmômetro modificado, um tanque classe A e um pluviômetro foram instalados na área experimental, o que permitiu o cálculo da $\mathrm{ET}_{0}$, utilizada como parâmetro para o cálculo do volume de água a ser aplicado em cada irrigação. Utilizou-se um turno de rega de dois dias.

Os efeitos dos tratamentos sobre a produtividade, peso médio dos frutos e número total de frutos foram avaliados pela pesagem e contagem de todos os frutos colhidos da área útil de cada parcela pelo menos duas vezes por semana, durante os períodos produtivos.

Para determinação das características qualitativas dos frutos, coletaram-se, em duas ocasiões, nos meses de maio e junho de 1997, seis frutos maduros por parcela. Nesses frutos foram determinados o comprimento, o diâmetro, a espessura da casca, a concentração de polpa, casca, suco, vitamina $\mathrm{C}$ e de ácido cítrico, o $\mathrm{pH}$ e o ${ }^{\circ} \mathrm{Brix}$ ( sólidos solúveis totais - SST)

$\mathrm{O} \mathrm{pH}$ foi determinado pela leitura direta de amostra do suco em potenciômetro digital; o ${ }^{\circ}$ Brix (SST), obtido com 
uso de um refratômetro manual; a acidez total titulável (ATT), expressa em g de ácido cítrico por $100 \mathrm{~mL}$ de suco, foi determinada a partir de $5 \mathrm{~mL}$ de suco, usando-se o indicador fenolftaleína, seguido por titulação com $\mathrm{NaOH}$ $0,1 \mathrm{~N}$; a vitamina $\mathrm{C}$, em mg de ácido ascórbico por $100 \mathrm{~mL}$ de suco, foi obtida através da titulação com 2,4 dinitrofenilhidrazina (2,4-D).

Os dados das variáveis estudadas foram submetidos à análise de variância (teste de F) e de regressão polinomial, em que foram adotados os níveis de significância de $1 \%$, $5 \%$ ou $10 \%$.

\section{RESULTADOS E DISCUSSÃo}

Não houve resposta ao incremento da adubação nitrogenada, tanto no tocante à produtividade quanto ao número de frutos, quando as lâminas de irrigação aplicadas foram correspondentes a 0, 25, $100 \mathrm{e}$ $125 \%$ da $\mathrm{ET}_{0}$ (Figs. 1 e 2). Isto sugere ter sido pouca ou nenhuma a eficiência da utilização do adubo nitrogenado quando não se utilizou a irrigação $\left(0 \%\right.$ da $\left.\mathrm{ET}_{0}\right)$, ou quando a lâmina de irrigação foi baixa $\left(25 \%\right.$ da $\left.\mathrm{ET}_{0}\right)$, ou quando esta lâmina foi muito alta $\left(100 \%\right.$ e $125 \%$ da $\left.\mathrm{ET}_{0}\right)$.

Quando há um déficit de água, nos casos específicos quando não se irrigou ou aplicou uma lâmina correspondente a $25 \%$ da $\mathrm{ET}_{0}$, a falta de resposta à adubação nitrogenada deve-se, provavelmente, às perdas provocadas possivelmente pela volatilização da $\mathrm{NH}_{3}$, e também por não haver água suficiente para levar o N, proveniente da hidrólise da uréia, para a zona de absorção das raízes. Ribeiro (1996) afirma que, quando aplicada em solo seco, a uréia absorve água do ar e inicia o processo de hidrólise, e, com o calor, a volatilização da amônia é favorecida.

É provável que a afirmação de Ribeiro (1996) sirva melhor para explicar o fato de não haver resposta à adubação com uréia em solo supostamente seco ou com baixo nível de umidade. Ribeiro (1996) sugere

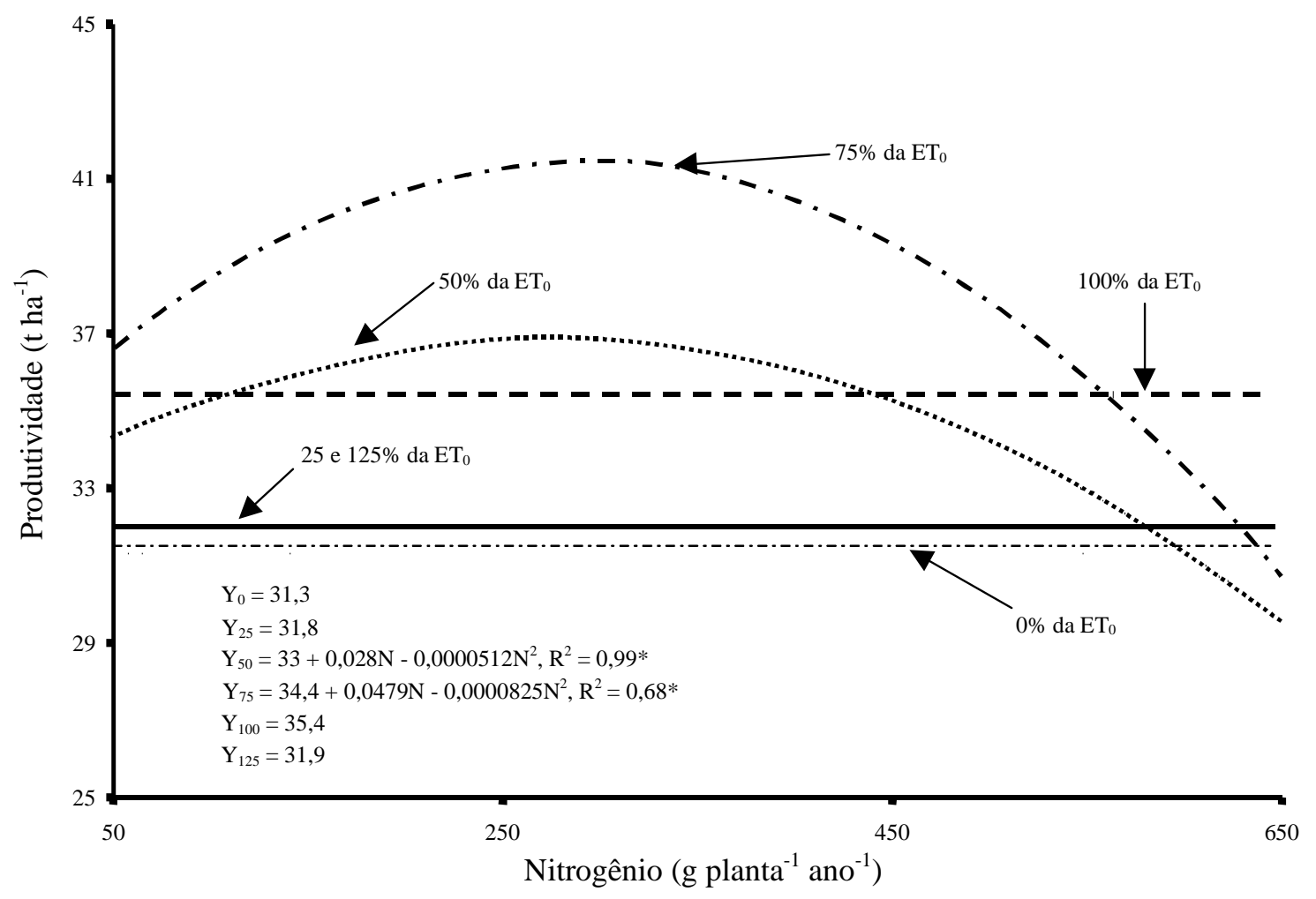

FIG. 1. Produtividade de frutos do maracujazeiro-amarelo em função de doses de nitrogênio sob lâminas de irrigação (\% da $\left.\operatorname{ET}_{0}\right)$. 


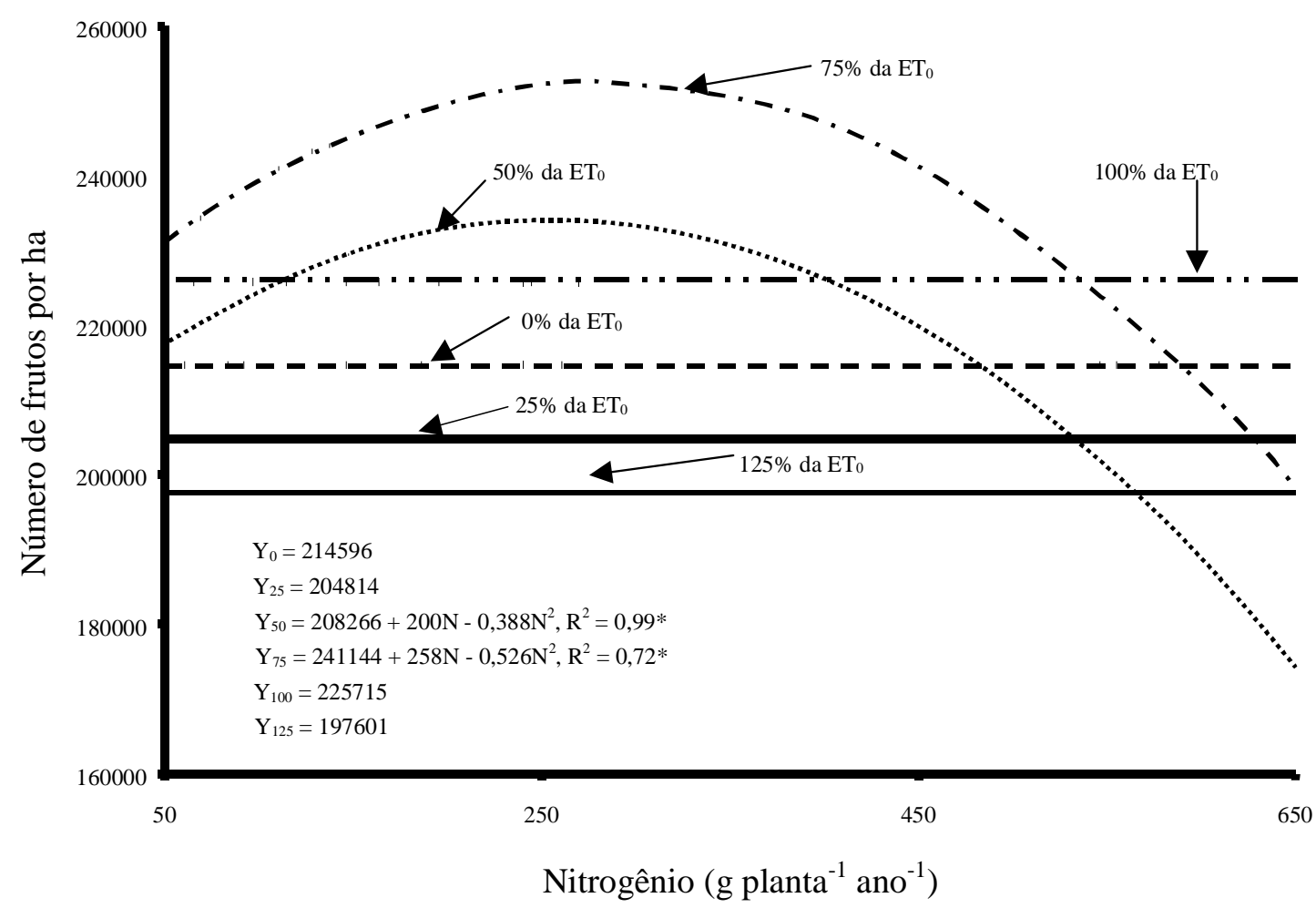

FIG. 2. Número de frutos por ha do maracujazeiro-amarelo em razão de doses de nitrogênio sob lâminas de irrigação (\% da $\left.\mathbf{E T}_{0}\right)$.

que a umidade do ar ou a água proveniente das camadas mais profundas do solo, que sobe por capilaridade, ou ainda, aquela adicionada em menor quantidade pela irrigação, possa ser insuficiente para incorporar a $\mathrm{NH}_{3}$ ao solo, mas suficiente para desencadear o processo de hidrólise da uréia. Assim, por não haver arraste desta amônia no perfil do solo, permitindo a sua retenção pelas argilas e/ou sua absorção pelas plantas, haveria perdas, possivelmente, por volatilização.

Quanto à falta de resposta no tocante à produtividade e ao peso médio dos frutos, a adubação nitrogenada quando as lâminas de irrigação foram elevadas, correspondentes a $100 \%$ e $125 \%$ da $\mathrm{ET}_{0}$ (Figs. 1 e 2), é possível que as perdas tenham sido provocadas pela lixiviação tanto do $\mathrm{NH}_{4}{ }^{+}$, proveniente da hidrólise da uréia, quanto do $\mathrm{NO}_{3}{ }^{-}$, proveniente da nitrificação do $\mathrm{NH}_{4}{ }^{+}$, pelo elevado volume de água aplicado ao solo. Ribeiro (1996) afirma que o amônio liberado da hidrólise da uréia, quando arrastado pelas camadas do solo, é retido pelas cargas da CTC. Entretanto, em solos arenosos, com baixa CTC, como o do experimento em questão, a retenção de cátions será baixa, fato também verificado por Kiehl (1989). Já o $\mathrm{NO}_{3}{ }^{-}$, além de não ser retido pela CTC do solo, é muito solúvel em água e, portanto, mais facilmente lixiviado.

Nas lâminas de irrigação onde a resposta ao $\mathrm{N}$ foi positiva quanto à produtividade (Fig. 1) e quanto ao número de frutos (Fig. 2), verifica-se um comportamento diferencial de acordo com o nível de umidade no solo. Quando foram aplicados $75 \%$ da $\mathrm{ET}_{0}$, numa lâmina total de água correspondente a $1.293 \mathrm{~mm}$, a dose de $\mathrm{N}$ necessária para a produção máxima foi de $290 \mathrm{~g} \mathrm{planta}^{-1}$ ano $^{-1}$, e a produtividade obtida nessas condições foi de 41,3 $\mathrm{t} \mathrm{ha}^{-1}$ de frutos. Quando se 
utilizou uma lâmina de água correspondente a 50\% da $\mathrm{ET}_{0}$, lâmina total de água correspondente a $1.195 \mathrm{~mm}$, a dose de $\mathrm{N}$ necessária para atingir a máxima produtividade foi de $273 \mathrm{~g} \mathrm{planta}^{-1} \mathrm{ano}^{-1}$, a qual foi estimada em $36,8 \mathrm{t} \mathrm{ha}^{-1}$. O aproveitamento do $\mathrm{N}$ proveniente da aplicação da uréia, pode ser maximizado se a água for usada em níveis adequados, o que sugere também que o próprio manejo pode evitar as perdas do fertilizante (Kiehl, 1996).

A dose de $\mathrm{N}$ que proporcionou o maior número de frutos foi de $245 \mathrm{~g}_{\text {planta }}{ }^{-1} \mathrm{ano}^{-1}$, aplicada sob lâmina de irrigação igual a $75 \%$ da $\mathrm{ET}_{0}$, numa lâmina total de água de $1.293 \mathrm{~mm}$. Quando foram utilizados $50 \%$ da $\mathrm{ET}_{0}$, num total de $1.195 \mathrm{~mm}$ de água, a dose de $\mathrm{N}$ necessária para a obtenção do maior número de frutos foi de $258 \mathrm{~g} \mathrm{planta}^{-1} \mathrm{ano}^{-1}$.

A provável causa do decréscimo no número de frutos quando da aplicação excessiva de fertilizantes nitrogenados é o fato de que, quando aplicado em períodos de florescimento, o $\mathrm{N}$ é alocado preferencialmente para crescimento vegetativo, resultando em excesso de folhagem e diminuição do número de flores. Isto foi observado em pêssego por Cummings (1988) e Weinbaum (1988), citados por Olienyk et al. (1997). Trabalhando em solução nutritiva, Menzel et al. (1991) observaram uma elevação no número de flores e no teor foliar de N, em plantas de maracujá, com o aumento nos níveis de $\mathrm{N}$ na solução.

Quando se considerou a média dos tratamentos com adubação nitrogenada, as lâminas de irrigação influenciaram significativamente a produtividade e o peso médio de frutos (Fig. 3). A maior produtividade observada foi de $35,5 \mathrm{t} \mathrm{ha}^{-1}$, obtida quando foram aplicados $72,3 \%$ da $\mathrm{ET}_{0}$, correspondendo a uma lâmina total de água igual a $1.282 \mathrm{~mm}$. Em relação ao peso médio de frutos, com máximo de $161 \mathrm{~g} \mathrm{fruto}^{-1}$, a

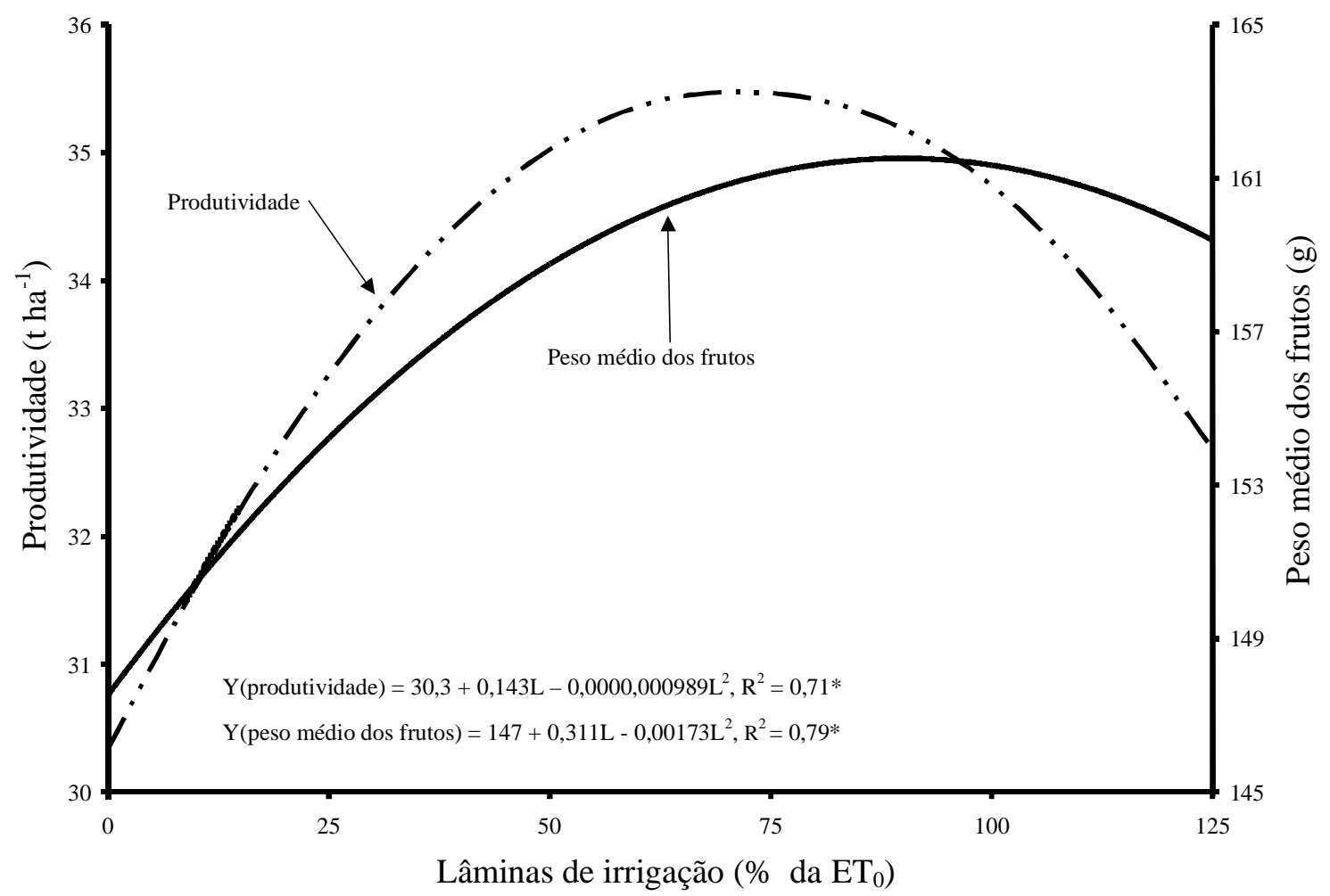

FIG. 3. Produtividade e peso médio (PM) dos frutos do maracujazeiro-amarelo, em função de lâminas de irrigação (\% da $\mathrm{ET}_{0}$ ), considerando a média dos tratamentos com adubação nitrogenada. 
lâmina foi de $89,8 \%$ da $\mathrm{ET}_{0}$, correspondendo a $1.404 \mathrm{~mm}$. O peso médio dos frutos não foi influenciado pela adubação nitrogenada

A adubação nitrogenada não influenciou nenhuma das características qualitativa dos frutos. Verificou-se, para cada $100 \mathrm{~g}$ de fruto, uma concentração média de $35,6 \mathrm{~g}$ de suco, 58,9 $\mathrm{g}$ de casca e 5,5 $\mathrm{g}$ de sementes. O diâmetro, o comprimento e a espessura média da casca foram iguais a 69,5, 73,7 e 6,4 mm, respectivamente.

Com relação à $\mathrm{ATT}$ e à vitamina $\mathrm{C}$, foram verificados, em média, 4,16 g de ácido cítrico e 16,9 mg de ácido ascórbico por $100 \mathrm{~mL}$ de suco, respectivamente. $\mathrm{O}^{\circ}$ Brix encontrado foi de $13,1 \mathrm{e} \mathrm{o} \mathrm{pH}$ de 2,6 . Haag (1992) alerta que a elevação dos teores foliares de N, com o incremento da adubação nitrogenada, tem pouca influência sobre o ${ }^{\circ}$ Brix, a ATT, a relação $\mathrm{SST} / \mathrm{ATT}$ e o teor de vitamina $\mathrm{C}$ em frutos de citros. Quanto à acidez, os resultados encontrados discordam dos de Müller (1977), que constatou maiores valores de ATT quando da aplicação de sulfato de amônio.

A utilização da irrigação aumentou o comprimento e o diâmetro do fruto até uma lâmina correspondente a $72,9 \%\left(\mathrm{Y}\left(_{\text {comprimento }}\right)=70,9+0,112 \mathrm{~L}-\right.$ $\left.0,000769 \mathrm{~L}^{2}, \mathrm{R}^{2}=0,73 *\right)$ e $77,1 \%(\mathrm{Y}($ diâmetro $)=68,1+$ $\left.0,0554 \mathrm{~L}-0,000359 \mathrm{~L}^{2}, \mathrm{R}^{2}=0,60 *\right) \mathrm{daET}_{0}$, respectivamente.

\section{CONCLUSÕES}

1. A produtividade máxima de frutos, $41,3 \mathrm{tha}^{-1}$, é obtida quando se aplica $290 \mathrm{~g} \mathrm{planta}^{-1} \mathrm{ano}^{-1}$ de N, sob uma lâmina de irrigação de $75 \%$ da $\mathrm{ET}_{0}$, o que corresponde a uma lâmina total de água (irrigação + precipitação efetiva) de $1.293 \mathrm{~mm}$.

2. Na irrigação correspondente a $50 \%$ da $\mathrm{ET}_{0}$, numa lâmina total de água igual a $1.195 \mathrm{~mm}$, a produtividade máxima obtida é de 36,8 t ha ${ }^{-1}$, com 273 g planta $^{-1}$ ano $^{-1}$ de N.

3. Não há resposta ao incremento do adubo nitrogenado quando se utilizam lâminas correspondentes a $0,25,100$ e $125 \%$ da $\mathrm{ET}_{0}$.

4. A adubação nitrogenada influencia o número de frutos ha-1 e não influencia o peso médio e outras características qualitativas dos frutos.

5. As irrigações influenciam a produtividade, o peso médio, comprimento e o diâmetro dos frutos do maracujazeiro-amarelo.

\section{REFERÊNCIAS}

AGRIANUAL 99: anuário da agricultura brasileira. São Paulo : Argos Comunicação, 1999. p.368-377

AGUIRRE, A.C.P. Nutrição mineral do maracujá amarelo (Passiflora edulis Sims f. flavicarpa). Piracicaba : USP-ESALQ, 1977. 116p. Dissertação de Mestrado.

BAUMGARTNER, G.; LOURENÇO, R.S.; MALAVOLTA, E. Estudos sobre a nutrição mineral e adubação do maracujazeiro (Passiflora edulis Sims f. flavicarpa Deg.).V. Adubação mineral. Científica, Jaboticabal, v.6, n.3, p.361-367, 1978.

BERNARDO, S. Manual de irrigação. Viçosa : Imprensa Universitária, 1995. 657p

FARIA, J.L.C.; COLAUTO, N.M.; MANICA, I.; STRONSKI, M. dos S.; APPEL, H.B. Efecto de tres dosis de $\mathrm{N}, \mathrm{P}$ y $\mathrm{K}$ en la producción de maracuyá amarillo (Passiflora edulis Sims f. flavicarpa Deg.) durante tres años de evaluacion en Guaíba-RS, Brazil Pesquisa Agropecuária Brasileira, Brasília, v.26, n.3, p.311-314, mar. 1991.

HAAG, H.P. Nutrição mineral e qualidade dos produtos agrícolas. In: REUNIÃO BRASILEIRADE FERTILIDADE DO SOLO E NUTRIÇÃO DE PLANTAS, 20., 1992, Piracicaba. Anais. Campinas : Fundação Cargill, 1992. p.405-425.

HAAG, H.P.; OLIVEIRA, G.D.; BORDUCCHI, A.S.; SARRUGE, J.R. Absorção de nutrientes por duas variedades de maracujá. Anais da Escola Superior de Agricultura Luiz de Queiroz, Piracicaba, n.30, p.267-279, 1973.

KIEHL, J.C. Comentário do artigo "Como evitar a perda do nitrogênio de adubos por volatização". Boletim Informativo, v.21, n.3, p.118-119, 1996.

KIEHL, J.C. Distribuição e retenção da amônia no solo após aplicação de uréia. Revista Brasileira de Ciência do Solo, Campinas, n.13, p.75-80, 1989.

MENZEL, C.M.; HAYDON, G.E.; DOOGAN, V.J.; SIMPSON, D.R. New standard leaf nutrient concentrations for passion fruit based on seasonal phenology and leaf composition. Journal of Horticultural Science, Ashord, v.68, n.2, p.215230, 1993

MENZEL, C.M.; HAYDON, G.E.; SIMPSON, D.R Effect of nitrogen on growth and flowering of passion

Pesq. agropec. bras., Brasília, v.35, n.6, p.1101-1108, jun. 2000 
fruit (Passiflora edulis $\mathrm{f}$. edulis $\times$ P. edulis $\mathrm{f}$ flavicarpa) in sand culture. Journal of Horticultural Science, Ashord, v.66, n.6, p.689-702, 1991

MENZEL, C.M.; SIMPSON, D.R.; DOWLING, A.J. Water relations in passion fruit: effect of moisture stress on growth, flowering and nutrient uptake. Scientia Horticulturae, Amsterdam, n.29, p.239249, 1986

MÜLLER, C.H. Efeitos de doses de sulfato de amônio e de cloreto de potássio sobre a produtividade e a qualidade de maracujás colhidos em épocas diferentes. Viçosa : UFV, 1977. 90p. Dissertação de Mestrado.

OLIENYK, P.; GONZALES, A.R.; MAUROMOUSTAKOS, A.; PATTERSON, W.K. Nitrogen fertilization affects quality of peach puree. HortScience, Alexandria, v.32, n.2, p.284-287, 1997.

RAIJ, B. van. Fertilidade do solo e adubação. Piracicaba Ceres/Potafos, 1991. 343p
RIBEIRO, A.C. Como evitar a perda do nitrogênio de adubos por volatilização. Boletim Informativo da Sociedade Brasileira de Ciência do Solo, Campinas, v.21, n.2, p.43-46, 1996.

RUGGIERO, C.; SÃO JOSÉ, A.R.; VOLPE, C.A.; OLIVEIRA, J.C. de; DURIGAN, J.F.; BAUMGARTNER，J.G.; SILVA，J.R. da; NAKAMURA, K.; FERREIRA, M.E.; KAVATI, R.; PEREIRA, V. da P. Maracujá para exportação: aspectos técnicos da produção. Brasília : EmbrapaSPI, 1996. 64p. (Publicações Técnicas Frupex, 19).

SILVA, J.R. da. Nutrição e adubação. In: SÃO JOSÉ,A.R. (Ed.). Maracujá: produção e mercado. Vitória da Conquista : Universidade Estadual do Sudoeste da Bahia, 1994. p.84-90

TEIXEIRA, D.M.M. Efeito de vários níveis de fertirrigação na cultura do maracujazeiro-amarelo ( $P$. edulis f. flavicarpa). Piracicaba : USP-ESALQ, 1989. 83p. Dissertação de Mestrado. 